\title{
SELECTION OF COAL TRANSPORTATION MODE FROM THE OPEN PIT MINE TO THE THERMIC POWER PLANT USING FUZZY ANALYTIC HIERARCHY PROCESS
}

\author{
Pinar Mizrak Özfirat ${ }^{1}$, Muharrem Kemal Özfirat ${ }^{2}$, Tahir Malli ${ }^{2}$ \\ ${ }^{1}$ Dept of Industrial Engineering, Celal Bayar University, Turkey \\ ${ }^{2}$ Dept of Mining Engineering, Dokuz Eylul University, Turkey
}

Submitted 29 July 2015; resubmitted 11 November 2015, 16 February 2016; accepted 5 March 2016; published online 12 April 2017

\begin{abstract}
Coal produced in open pit mines should be moved to thermic power plants for production of power. Thermic power plants require very large amounts of coal. In transportation process of this coal, both costs and technical parameters should be considered. Common alternative transportation modes in this process are belt conveyors, truck types, suspension rail conveying systems, pipelines and railways. Selection of one of these modes is influenced by transportation distance, inclination of the haulage road, amount of coal reserve, investment costs, production capacity and unit production cost of the open pit mine. In this study, advantages and disadvantages of alternative transportation modes are analysed using Fuzzy Analytic Hierarchy Process (F-AHP). The results revealed, belt conveyors and trucks transportation by are superior to others.
\end{abstract}

Keywords: transportation mode; fuzzy analytic hierarchy process (F-AHP); fuzzy goal programming (FGP); coal; open pit; thermic power plant.

\section{Notations}

Sets:

$i, j$ - set of decision criterion, $1 \ldots . . n$.

Parameters:

$L_{i}$ - lower bound for criterion $i$;

$M_{i}$ - mid-value for criterion $i$ (doesn't have to be mathematical average of $L_{i}$ and $\left.U_{i}\right)$;

$U_{i}$ - upper bound for criterion $i$.

Decision variables:

$\lambda$ - decision variable concerned with fuzzy membership functions;

$W_{i}$ - final priority (importance coefficient) of criteria $i$;

$S_{i j}$ - deviational variable of $W_{i}$ from $W_{j}$ considering the pairwise comparison value of criterion $i$ and $j$.

\section{Introduction}

In today's mining operations, increasing competition, decreasing mine reserves and quality (tenor, calorie, ppm etc.) require mining costs to be very efficiently controlled. Therefore mining operations, equipment and machinery must be optimized.
One of the major cost components in open pit mining is the transportation of produced coal. Thermic power plants demand very large amounts of coal. Transportation of these large amounts from the open pit mine to the power plant also require large capacities of transportation equipment (Lizotte 1988; Çebi 1995).

Transportation costs nearly make up $50 \%$ of total operation costs in Turkey. Therefore, decreasing transportation costs by a few points would save the mine considerable amount of money (Malli 2013).

In addition, there exist both physical and economical constraints in transportation of coal. Therefore, determining on the most suitable transportation mode is not a trivial process. It depends on the unique characteristics of the mine as well as the properties of alternative transportation modes.

In this study, a number of alternative haulage techniques to transport coal form an open pit mine to the thermic power plant are considered and in order to select the optimum transportation mode, Fuzzy Analytic Hierarchy Process (F-AHP) is used.

Analytic Hierarchy Process (AHP) is a well-known and widely used Multi-Criteria Decision-Making (MCDM) approach. It has applications in many dif-

Corresponding author: Pinar Mizrak Özfirat

E-mail: pinar.ozfirat@cbu.edu.tr 
ferent areas (Içtenbaş, Rouyendegh 2012; Rouyendegh, Erkan 2012; Rouyendegh, Lesani 2014). Incorporating fuzzy techniques into AHP makes the decision process less dependent to decision makers and therefore, human error can be decreased within the decision process. In addition, imprecision and vagueness can be incorporated into comparison of alternatives by use of fuzzy numbers. Therefore, fuzzy numbers have found large application in MCDM methods. Some of these are F-AHP (Mikhailov, Tsvetinov 2004, Ozfirat 2012, 2015b; Mizrak Ozfirat 2014), Fuzzy Technique for Order of Preference by Similarity to Ideal Solution (F-TOPSIS) (Mahdevari et al. 2014), Fuzzy ELimination Et Choix Traduisant la REalité (F-ELECTRE) (Chen, Xu 2015), Fuzzy Preference Ranking Organization METHod for Enrichment of Evaluations (F-PROMETHEE) (Elevli 2014) and fuzzy cognitive network process (Yuen 2014).

The proposed F-AHP procedure is integrating AHP with fuzzy triangular numbers. There are a number of different prioritization methods for the membership functions in F-AHP. These are discussed in Yuen (2012). In this study, fuzzy prioritization method of Mikhailov and Tsvetinov (2004) is employed. Then, a Fuzzy Goal Programming (FGP) model is built and solved to find the final priorities of the decision criteria.

In this study, transportation modes from the open pit mine to the thermic power plant are considered. Seven main decision criteria; namely transportation distance, inclination, ore reserve amount, economic life, investment cost, production capacity and unit cost; and seven alternative haulage systems; belt conveyors, truck haulage (with small, medium and large capacity), suspension rail conveying systems, pipelines and railway; are defined. The priorities of all decision criteria are found by the proposed F-AHP approach and finally, overall performance scores are computed for each of the alternative transportation modes.

To the best of our knowledge, this study is the first one which applies F-AHP to transportation mode selection in mining. In addition, the proposed approach integrates F-AHP and FGP, which provides the reader an alternative approach for different selection problems. Therefore, the paper is of interest to mining researchers and practitioners as well as fuzzy selection researchers in any area.

The rest of the paper is organized as follows. In section 1, alternative transportation modes for the case are given briefly. In section 2, the proposed F-AHP ap- proach is explained in detail. Section 3 and 4 gives the case study and computational results and discussions respectively. Finally, conclusion is given.

\section{Alternative Transportation Modes}

Haulage is simply transportation of mass from one location to the other. Haulage is an important operation in mining. Ore must be transported from the mine to the ore dressing plant, thermic power plant and spoilage area or to the consumer.

There are number of alternative techniques for transportation of coal from the mine to the thermic power plant. Among these techniques are belt conveyors, trucks, suspension rail conveying systems, pipelines and railway systems. In order to select one of these systems, a number of factors should be considered. These decision factors are transportation amount, transportation distance, inclination of road, geotechnical and topographic characteristics of the field, physical properties of coal - density, humidity ratio, particle size, etc. (Simsir et al. 2013).

Haulage can be made in vertical, horizontal or inclined axis and two or more modes can be used together in many cases. Technical and economical characteristics of haulage systems are given in Table 1. It can be seen that the smallest investment cost belongs to truck haulage. However, the smallest unit cost belongs to pipeline. Also, the inclination and transportation distance values differ according to the transportation mode. Therefore, determining the type of transportation mode or modes to use is not a trivial process. In addition, the decision makers must decide 'which of these factors are influencing the decision and how much. Considering all these conflicts, F-AHP is determined to be a useful and efficient tool to solve the problem.

The graph given in Fig. 1 shows the preference areas of each haulage system according to transportation demand (amount of coal to be transported [tons/h]) and distance. As seen from Fig. 1, in selection of haulage techniques the most important factor is transportation demand. If the amount of coal to be transported is low, truck transportation is the most economical technique in all distances. In many of small-scale mine firms, truck transportation is preferred since it needs smaller investment cost. On the other hand, belt conveyors need higher investment costs but they have lower operation costs. As the distance of transportation decreases, belt convey-

Table 1. Characteristics of haulage techniques (Karpuz 2005; Thompson, Raymer 1981)

\begin{tabular}{|c|c|c|c|c|c|c|}
\hline \multirow{2}{*}{ Method } & \multirow{2}{*}{ Operation } & \multirow{2}{*}{ Distance $[\mathrm{km}]$} & \multicolumn{2}{|c|}{ Grade ability } & \multirow{2}{*}{$\begin{array}{l}\text { Investment cost } \\
{[\text { million \$] }}\end{array}$} & \multirow{2}{*}{$\begin{array}{c}\text { Unit cost } \\
\text { [cent/ton-km] }\end{array}$} \\
\hline & & & Average $\left[{ }^{\circ}\right]$ & $\operatorname{Max}\left[^{\circ}\right]$ & & \\
\hline Belt conveyor $A 1$ & continuous & $0.3-100$ & 17 & 35 & $2-3$ & $4-8$ \\
\hline Truck $A 2-A 3-A 4$ & cyclic & $0.3-8$ & 8 & 12 & $1.5-2.5$ & $6-14$ \\
\hline Suspension rail $A 5$ & cyclic & $0.8-8$ & 5 & 45 & $5-7$ & $30-40$ \\
\hline Pipeline $A 6$ & continuous & unlimited & - & - & $3-4$ & $2-5$ \\
\hline Railway $A 7$ & cyclic & unlimited & 2 & 3 & $4-4.5$ & $20-30$ \\
\hline
\end{tabular}




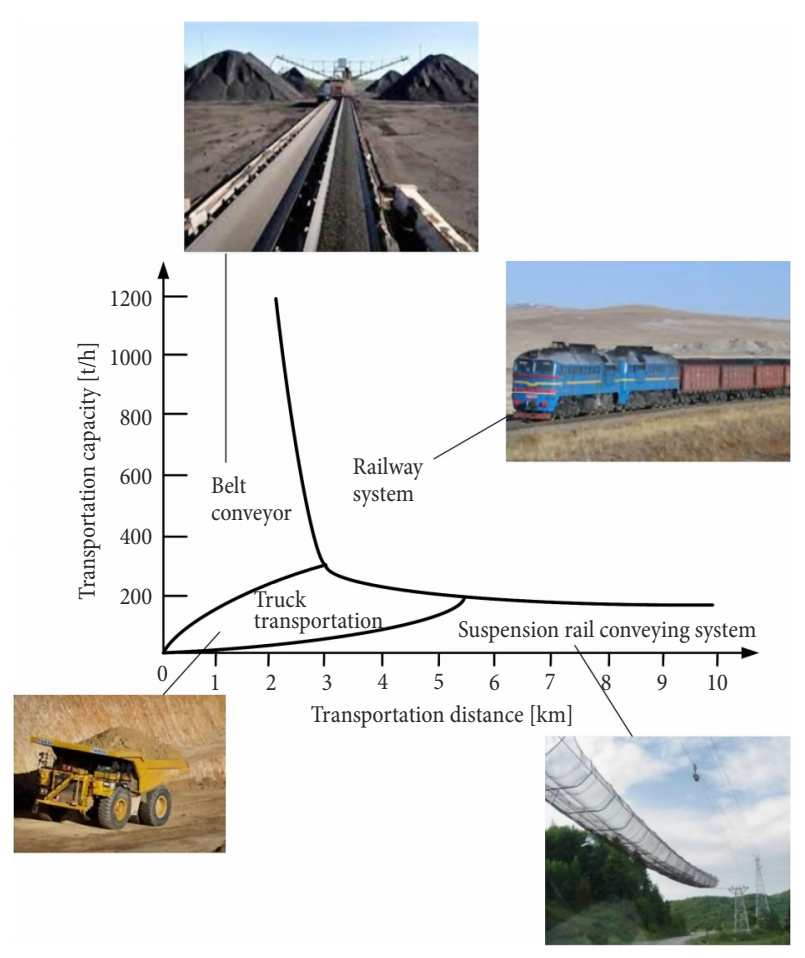

Fig. 1. Preference areas of haulage techniques according to transportation demand and distance (Kose et al. 2009)

ors turn out to be more economical. In addition, as the mine gets deeper and production amount increases, belt conveyors are again preferred (Kose et al. 2009).

Alternative haulage systems considered in this study are explained briefly in the following:

- Belt conveyors (A1): Belt conveyors are continuous transportation systems which are made up of two drums and an infinite belt in between them. Since their introduction in the first half of the 20th century, belt conveyors have become indispensable in the layout of facilities due to their simplicity, universality, and reliability. Belt conveyors allow optimal use of floor space and maximum flexibility in the design of the material flow scheme. While capital cost comparisons between conveyor and truck haulage are dependent on the application, operating costs of a conveyor system are far lower (Demirsoy 1984; Walker 2012; Yegulalp 2005; Zamorano 2011).

Another advantage of belt conveyors is adaptability to the physical conditions of the field. For example, belt conveyors can easily move in fields up to $35 \%$ inclination, whereas trucks can be used in field at most $8-12 \%$ inclination (Table 1). Today 20000 tons of ore (approximately 1000 truck load) can be moved for $100 \mathrm{~km}$ using belt conveyors at $10 \%$ cost of truck transportation (Ozfirat 2015a).

In general, the larger the throughput of the system, the greater the operational savings when compared with an equivalent truck operation. Current technology allows single-flight belts with lengths from 20 to $30 \mathrm{~km}$; the longest system in use is $100 \mathrm{~km}$ long (Zamorano 2011).

- Truck Haulage: Another type of transportation for mine operations is truck haulage. Large offroad trucks have reached capacities of up to 364 tons with gross machine weights around 625 tons. In the past, large off-road trucks were mostly diesel-electric, with Direct Current (DC) wheel drives; however, the newer, larger trucks have mechanical transmissions or Alternate Current (AC) wheel drives. Recent developments include autonomous trucks for both underground and surface operations that are aimed at increasing reliability and safety while reducing labour requirements (Karpuz 2005; Saltoglu 2005; Zamorano 2011).

Trucks for surface mining currently have payload capacities from 50 to 360 tons. In this study, these trucks are classified as small capacity trucks ( $\mathrm{ca}$ pacity $<90$ tons, $A 2$ ), medium capacity trucks (90 tons < capacity < 220 tons, A3) and large capacity trucks (capacity $>220$ tons, A4) for transportation to thermic power plant.

Truck haulage is preferable if facility establishment time is desired to be short, ore reserve is small or it is not possible to build up a railway or belt conveyor system. However, there are many disadvantages of truck haulage. These are short useful lives of tires, high costs of tires (up to 20\% of total cost), high maintenance and repair costs of trucks, high labour costs and dependency on outdoor (climate) conditions (Fig. 2).

- Suspension rail conveying system (A5): These systems are moving buckets, through a wire cable between towers in the air. This is a quite an old system which is most suitable for a field full of natural obstacles. Cableways are far more costly compared to other transportation modes. Therefore, they are only used in fields where it is not possible to apply other techniques. The only advantage of cableways compared to other modes is that it can be used over fields up to $45^{\circ}$ inclination, over canyons and rivers easily. Transportation by cableways is not affected by climate, however, the capacity is very limited, investment costs are very high and a breakdown in any part of the system would stop the whole transportation.

- Pipeline (A6): Pipelines are known to be used mostly for oil and gas transportation (Dogru 2005). However, it is the cheapest transportation technique so it is getting more in use in mining industry. It is simply movement of solid materials within a liquid. The important point is that solid-liquid mixture should be close to homogeneous in order to have fluid behaviour of an ideal liquid. By this way, energy would be used at the minimum level. The cheapest liquid to move ore is water. Another point is that the ore to be moved should not change physical and/or chemical properties in water. Therefore, the type 
of ores to be transported by pipelines is limited. These are coal, limestone, copper, iron, gilsonite, phosphate and nickel. However, lignite and coked coal cannot be moved by pipelines because it is not easy to refine these ores from water at the destination point.

- Railway (A7): Railway is one of the oldest transportation systems. The advantages are large capacity, safety and low cost in long distances. However, it is not possible to use railways in even medium inclinations and it is not economical in short distances.

Haulage system is determined at the design and planning stage of the mine. The seven alternative haulage systems defined above are considered using F-AHP. Decision criteria are transportation distance $(C 1)$, inclination of the transportation route $(C 2)$, ore reserve amount (C3), economic life of the mine (C4), investment costs $(C 5)$, production capacity or similarly transportation demand (C6) and unit cost (C7). Decision criteria and alternatives can be seen in the hierarchy in Fig. 3 .

\section{F-AHP Methodology}

The methodology has two main phases. In the first phase the decision makers form the pairwise comparison matrix using fuzzy triangular numbers and AHP is used to find lower, upper bounds and mid values of priorities. Then in the second phase, a FGP model is built. Lower, upper and mid values of priorities (found in the first phase) and the fuzzy triangular numbers are input into the model and the final priorities of each criteria are computed. Finally, in the decision phase, the weighted sum of ratings belonging to each alternative are calculated where the weights are the ones from FGP model. (Mizrak Ozfirat et al. 2015; Yetkin et al. 2016). The detailed step-by-step approach is given below.

\subsection{Determine Selection Criteria and Alternatives}

In most of selection problem, the first step is to determine the criteria which we will depend our selection. Then the alternatives among which we will make a se-

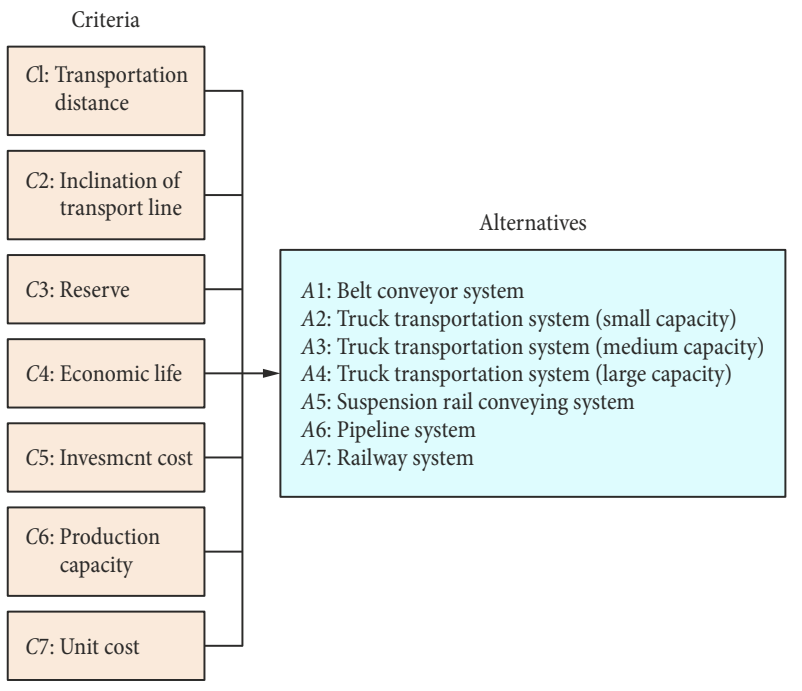

Fig. 3. Main decision criteria and alternative transportation modes

lection are listed. Let $C$ represent the decision criteria matrix made up of $n$ decision criteria from $C_{1}$ to $C_{n}$ as in Eq. (1). Similarly, let $K$ represent the transportation modes matrix made up of $k$ alternative transportation modes from $K_{1}$ to $K_{k}$ as in Eq. (2) (Mizrak Ozfirat et al. 2015).

$$
\begin{aligned}
C & =\left[C_{1}, C_{2}, C_{3}, \ldots, C_{n}\right] ; \\
K & =\left[K_{1}, K_{2}, K_{3}, \ldots, K_{k}\right] .
\end{aligned}
$$

\subsection{Build Pairwise Comparison Matrix Using Fuzzy Triangular Numbers}

In building the pairwise comparison matrix, fuzzy triangular numbers are used. Therefore, for each comparison of $c_{i}$ and $c_{j}$, a lower bound, an upper bound and a value in between these two (mid-value) values are determined. The pairwise comparison matrix $A$ is built as in Eq. (3). Saaty's (1980) scale of 9 is used to determine the values of $l_{i j}, m_{i j}$ and $u_{i j}$ (Mizrak Ozfirat et al. 2015).
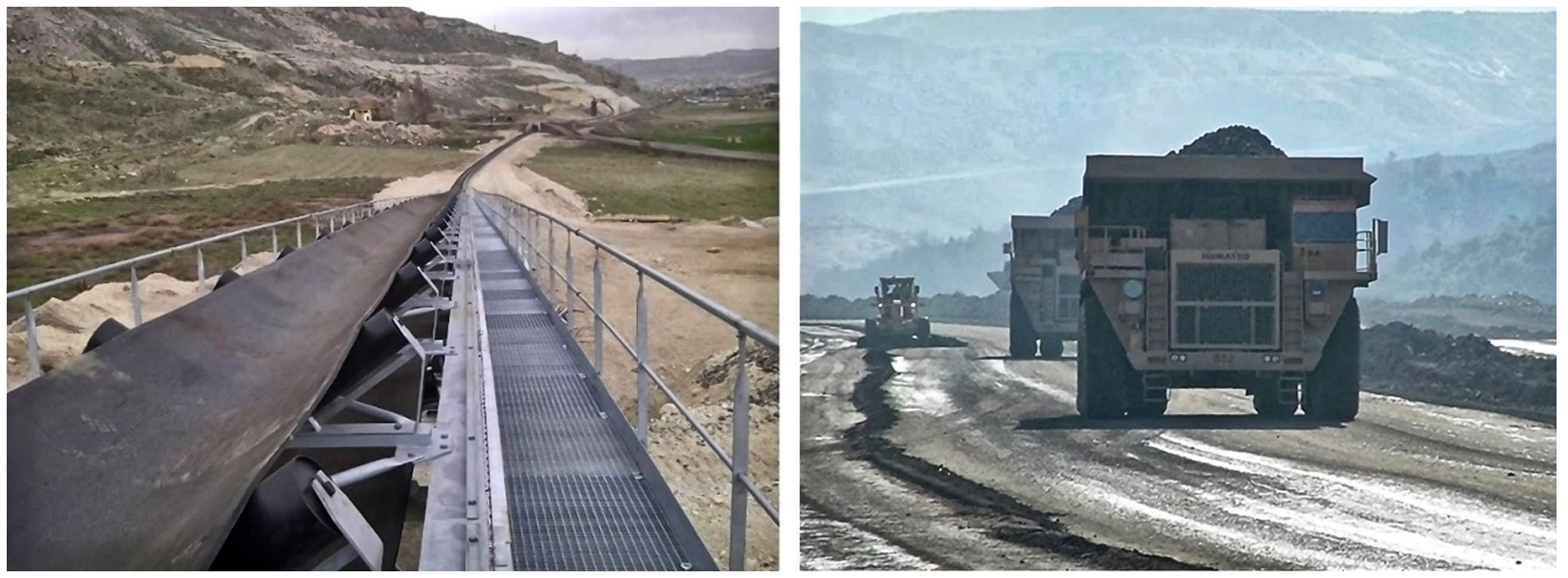

Fig. 2. Belt conveying and truck haulage (TKI 2015) 


$$
A=\left[\begin{array}{cccc}
(1,1,1) & \left(l_{12}, m_{12}, u_{12}\right) & \ldots & \left(l_{1 n}, m_{1 n}, u_{1 n}\right) \\
& (1,1,1) & \ldots & \left(l_{2 n}, m_{2 n}, u_{2 n}\right) \\
& & (1,1,1) & \left(l_{n-1, n}, m_{n-1, n}, u_{n-1, n}\right) \\
& & & (1,1,1)
\end{array}\right]
$$

\subsection{Find Lower Bounds, Mid-Values and Upper Bounds of Priorities}

Three set of priorities for each decision criterion are computed using lower, middle and upper values in matrix $A$ (Eq. (3)) by AHP. Let the set of priorities found using $l_{i j}$ (from matrix $A$ in Eq. (3)) comparisons be LowerBounds matrix as in Eq. (4). Similarly, let the set of priorities found using $m_{i j}$ and $u_{i j}$ (from matrix $A$ in Eq. (3)) comparisons be MidValues and UpperBounds matrices, as in Eqs (5) and (6), respectively. These sets add up to 1 in their own set (since the sum of priorities should be 1). In addition, it should be noted that mid-values do not have to be the arithmetic mean of lower and upper bounds. These values are in-between lower and upper bounds (Mizrak Ozfirat et al. 2015):

$$
\begin{aligned}
& \text { LowerBounds }=\left(L_{C 1}, L_{C 2}, L_{C 3}, \ldots, L_{C n}\right) ; \\
& \text { MidValues }=\left(M_{C 1}, M_{C 2}, M_{C 3}, \ldots, M_{C n}\right) ; \\
& \text { UpperBounds }=\left(U_{C 1}, U_{C 2}, U_{C 3}, \ldots, U_{C n}\right) .
\end{aligned}
$$

\subsection{Build FGP Model}

In the proposed methodology, the membership function of the fuzzy triangular number used in the model is given in Eq. (7) (Zadeh 1965; Mizrak Ozfirat et al. 2015):

$\mu_{i}(x)= \begin{cases}0 & \text { if } W_{i}(x) \leq L_{i}(x) \text { or } W_{i}(x) \geq U_{i}(x) ; \\ \frac{W_{i}(x)-L_{i}(x)}{M_{i}(x)-L_{i}(x)} & \text { if } L_{i}(x) \leq W_{i}(x) \leq M_{i}(x) ; \\ \frac{U_{i}(x)-W_{i}(x)}{U_{i}(x)-M_{i}(x)} & \text { if } L_{i}(x) \leq W_{i}(x) \leq M_{i}(x),\end{cases}$

$\forall i=1 \ldots n$.

In FGP model the first objective is to maximize the values of all membership functions. Therefore, we should maximize the minima of membership functions as in Eq. (8) (Mizrak Ozfirat et al. 2015):

$$
Z=\max _{i \in\{1 \ldots n\}} \mu_{i}(x) .
$$

By introducing an auxiliary variable $\lambda$, the model can be developed. The value of $\lambda$ needs to be less than $\mu_{i}(x)$ for all criteria and the model should maximize the value of $\lambda$. In the proposed model instead of maximizing $\lambda$, is minimized $-\lambda$.

In addition to minimizing $-\lambda$, there is a second objective in the model. The fuzzy triangular comparisons made in the first step is desired to be reflected into the model directly. Therefore, we want to minimize the deviations from these comparisons. In order to represent these deviations, another decision variable $S_{i j}$ is added into the model. The FGP model developed in the methodology is given in Eqs (9)-(17) (Mizrak Ozfirat et al. 2015).

$$
\begin{aligned}
& \text { Model: } \\
& \text { minimize } \sum_{i=1}^{n} \sum_{j=1}^{n} s_{i j}-\lambda ; \\
& L_{i} \leq W_{i} \leq U_{i}, \forall i=1 \ldots n ; \\
& \lambda \leq \frac{W_{i}-L_{i}}{M_{i}-L_{i}}, \forall i=1 \ldots n ; \\
& \lambda \leq \frac{U_{i}-W_{i}}{U_{i}-M_{i}}, \forall i=1 \ldots n ; \\
& \sum_{i=1}^{n} W_{i}=1 ; \\
& M_{i j} \cdot W_{j}=W_{i}+S_{i j}, \forall i, j=1 \ldots n: M_{i j} \geq 1 ; \\
& \left(\frac{1}{M_{i j}}\right) \cdot W_{i}=W_{j}+S_{i j}, \forall i, j=1 \ldots n: M_{i j} \prec 1 ; \\
& 0 \leq S_{i j} \leq 1, \forall i, j=1 \ldots n ; \\
& 0 \leq \lambda \leq 1 .
\end{aligned}
$$

As mentioned previously, the objective function is to minimize the deviations from the fuzzy comparisons of decision criteria and to minimize $-\lambda$ in Eq. (9). Eq. (10) expresses that the priorities of decision criteria should be between lower and upper bounds specified in phase I. Eq. (11) and Eq. (12) denotes that the values of membership functions should be maximized. Eq. (13) statisfies the sum of all decision criteria should be 1. By Eqs (14) and (15) the deviations from pairwise comparisons are defined. Finally, Eqs (16) and (17) define the decision variables domains. The FGP model is solved to give the final priorities for all decision criteria (Mizrak Ozfirat et al. 2015; Yetkin et al. 2016). In addition, the value of $\lambda$ in the model gives us the level of consistency. In the classical AHP inconsistency level should be less than 0.1, which means consistency level should be greater than 0.9 . Therefore, in the model value of $\lambda$ is desired to be greater than 0.9 .

\subsection{Find Overall Score of Each Alternative}

At this step, the alternatives listed should be given performance ratings according to each decision criteria. In other words, performance of each alternative according to each criterion should be rated. The scores matrix $R$ is given in Eq. (18). These ratings are determined to be over 100. By using a broad range of scores (scale of 100) the differences between alternatives can be revealed more clearly (Mizrak Ozfirat et al. 2015).

$$
R=\left[\begin{array}{cc}
R_{11} \cdots & R_{1 n} \\
\vdots & \vdots \\
R_{k 1} \cdots & R_{k n}
\end{array}\right] .
$$


The final score FinalScore of each alternative is found by weighted sum of individual scores as in Eq. (19). The weights $W$ are the final priorities of decision criteria found by the FGP model. Individual scores $R$ are the scores in Eq. (18) (Mizrak Ozfirat et al. 2015.

$$
\text { Finalscore }=R \cdot W \text {. }
$$

\section{Case Study}

Soma is located on the northwest of Aegean region within Manisa city (Turkey). Soma coalfields are generally rough fields. Lowest level is $+250 \mathrm{~m}$ and highest level is $+1201 \mathrm{~m}$. Location of the mine and thermic power plant can be seen in Fig. 4. Coal will be transported from Denis sector (Fig. 4) to the thermic power plant. Technical properties of the mine and the alternative transportation modes are given in Table 2. These values are determined as a result of field studies and field experiments at the region under study. It can be seen from Table 2 that the reserve amount of coal is nearly 700 millions of tons. Within the current operation of the mine, yearly production capacity is nearly 13 millions of tons. Therefore, economic life of the mine is expected to be at least 50 years (TKI 2015).

In addition, the technical properties belonging to each alternative transportation mode can be seen in Table 2 (Investment costs and unit costs are given in Table 1). Transportation distances are different for each transportation mode due to the physical properties of the field. The lowest distance belongs to suspension rail conveying system $A 5$ and the longest distance belongs to railway $A 7$. Corresponding inclinations of the routes are also given. Considering all of these values, the performance scores of each alternative for each decision criteria are determined as in Table 3 . The scores are determined by the decision makers of the system (over 100).

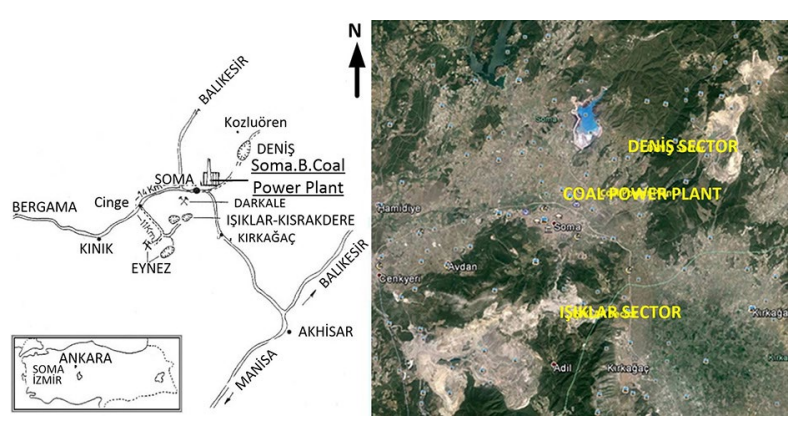

Fig. 4. Location of reserve areas and thermic power plant

Performance values on $C 1$ (transportation distance) and $C 2$ (inclination) are determined based on the operation data of each transportation mode given in Table 2. For example, the lowest distance belongs to suspension rail conveying system $A 5$. Therefore, the highest performance score belongs to $A 5$ for 'transportation distance' criterion (line $C 1$ in Table 3, performance score of $A 5$ is determined to be 90). In the other end, since the longest distance belongs to railway $A 7$, the lowest performance score belongs to $A 7$ for transportation distance criteria (line $C 1$ in Table 3, performance score of $A 7$ is determined to be 60).

In addition, performance values on $C 5$ (investment cost) and $C 7$ (unit cost) are determined based on the data of each transportation mode given in Table 1. For example, it can be seen from Table 1 that investment cost of suspension rail conveying system $A 5$ is highest so performance score of $A 5$ for 'investment cost' criterion is lowest (line $C 5$ in Table 3, performance score of $A 5$ is determined to be 50). In addition, investment costs of truck haulage $A 2-A 3-A 4$ is lowest, so performance score of these alternatives for 'investment cost' criterion are determined to be higher than other alternatives (line C5 in Table 3).

Table 2. Site operation data

\begin{tabular}{|l|c|c|c|c|c|}
\cline { 2 - 6 } \multicolumn{2}{|l}{} & \multicolumn{2}{l|}{$\begin{array}{l}\text { Reserve amount: } 688076700 \text { tons } \\
\text { Economic life: 50 years } \\
\text { Production capacity: } 12876832 \text { tons/year }\end{array}$} \\
\hline Parameters & Belt conveyor $A 1$ & Truck haulage $A 2-A 3-A 4$ & Suspension rail A5 & Pipeline A6 & Railway A7 \\
\hline Transportation distance [m] & 6000 & 8000 & 4000 & 5000 & 11000 \\
\hline Inclination [\%] & 3.88 & 6.2 & 5 & 4.5 & 0.5 \\
\hline
\end{tabular}

Table 3. Performance scores of alternative transportation modes according to each decision factor

\begin{tabular}{|l|c|c|c|c|c|c|c|}
\cline { 2 - 8 } \multicolumn{1}{c|}{} & $\begin{array}{c}\text { Belt } \\
\text { conveyor } A 1\end{array}$ & $\begin{array}{c}\text { Truck type 1 } \\
(\text { small })-A 2\end{array}$ & $\begin{array}{c}\text { Truck type 2 } \\
(\text { medium })-A 3\end{array}$ & $\begin{array}{c}\text { Truck type 3 } \\
\text { (large }-A 4\end{array}$ & $\begin{array}{c}\text { Suspension } \\
\text { rail } A 5\end{array}$ & $\begin{array}{c}\text { Pipeline } \\
A 6\end{array}$ & $\begin{array}{c}\text { Railway } \\
A 7\end{array}$ \\
\hline$C 1$ - transportation distance & 85 & 80 & 80 & 80 & 90 & 85 & 60 \\
\hline$C 2$ - inclination & 80 & 70 & 70 & 70 & 85 & 80 & 40 \\
\hline$C 3$ - reserve & 90 & 70 & 75 & 85 & 65 & 70 & 70 \\
\hline$C 4-$ economic life & 95 & 70 & 75 & 80 & 60 & 50 & 80 \\
\hline$C 5$ - investment cost & 70 & 90 & 85 & 80 & 50 & 60 & 55 \\
\hline$C 6$ - production capacity & 90 & 70 & 80 & 85 & 70 & 65 & 60 \\
\hline$C 7$ - unit cost & 90 & 80 & 85 & 90 & 60 & 65 & 55 \\
\hline
\end{tabular}


Performance values on the other three criteria (C3 - reserve, C4 - economic life, C6 - production capacity) are determined in the same manner. For example, highest production capacity is provided by belt conveyor $A 1$, so highest performance value belongs to belt conveyor $A 1$. Lowest capacity transportation mode is the railway $A 7$, so the lowest performance belongs to railway $A 7$.

\section{Computational Results and Discussions}

Fuzzy pairwise comparison matrix for the seven decision criteria is given in Table 4. There are different group decision-making procedures. Some of these also employ fuzzy techniques (Rouyendegh 2012). In this study, the comparison matrix is created by three mining engineers who are experts of transportation in mining. Delphi method (Nahmias 1997) is used to finalize the matrix. After finding the three set of priorities using fuzzy triangular numbers, FGP model is built and solved. The weight coefficients of each criteria are computed by the model. Priorities belonging to decision criteria can be seen in Fig. 5. As seen from the figure, the most effective factor on transportation mode is the transportation distance. The priority of this factor is found to be 0.267 . Then comes inclination of the route and reserve amount. These two factors are also influencing transportation mode decision much. Investment cost and unit cost have rather small effect. Finally, economic life of the mine and transportation capacity are nearly not affecting the decision at all.

In addition, $\lambda$ value which shows the consistency level is found to be 0.93 (from the FGP model) which is an acceptable level (consistency level should be greater than 0.9).

If classical AHP is employed instead of F-AHP, keeping the consistency level above 0.9 would be harder. In order to increase consistency, undesirable moves may be made. However, in F-AHP, even if the decision makers make mistakes, the process is eligible to decrease the effect of these mistakes on the results. By this way, selection process becomes less dependent to decision makers and less prone to errors.

In order to compute the final scores of each alternative transportation mode, performance values are multiplied by weight coefficients. The final scores of the seven alternative transportation modes are given in Fig. 6. As

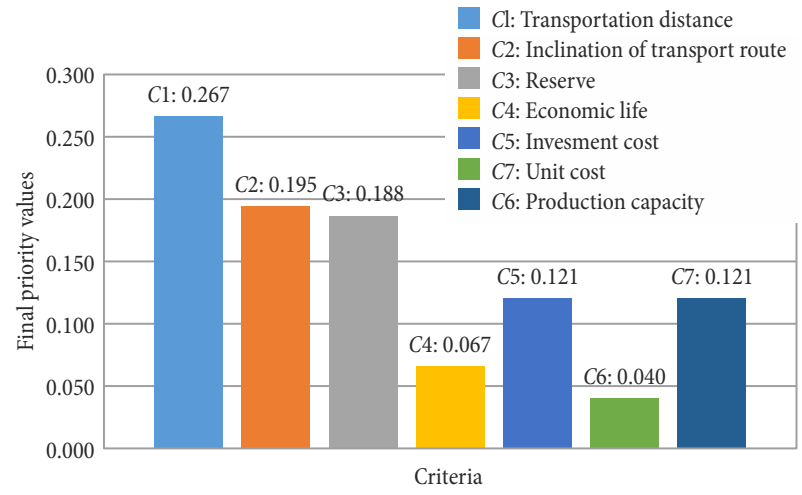

Fig. 5. Priorities of decision criteria

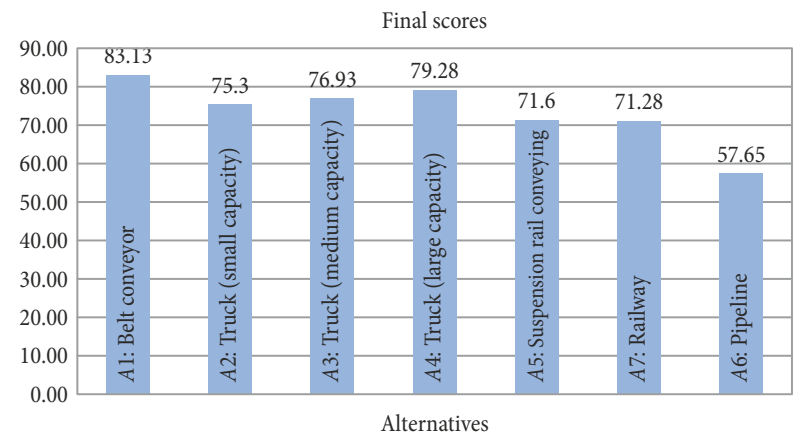

Fig. 6. Final Performance scores of alternative transportation modes

seen in the figure, belt conveyor system is found to be the best performing system in the overall. Second highest score belongs to large truck type $A 4$. The rest of the alternatives are ordered as medium truck type $A 3$, small truck type $A 2$, suspension rail conveying system $A 5$, pipeline $A 6$ and railway $A 7$.

\section{Conclusions}

In this study, F-AHP is used to select the most suitable haulage system from a coal mine to the thermic power plant. In the proposed F-AHP approach, pairwise comparison matrix among the decision criteria are prepared using fuzzy triangular numbers. Then using lower, upper and middle values of weight coefficients, final weights are computed using a FGP model.

Table 4. Pairwise comparisons using fuzzy triangular numbers

\begin{tabular}{|c|c|c|c|c|c|c|c|}
\hline Criteria & $C 1$ & $C 2$ & $C 3$ & $C 4$ & $C 5$ & $C 6$ & $C 7$ \\
\hline$C 1$ & $(\mathbf{1}, \mathbf{1}, \mathbf{1})$ & $(2,3,4)$ & $(1,2,3)$ & $(3,4,5)$ & $(2,3,4)$ & $(4,5,6)$ & $(1,2,3)$ \\
\hline$C 2$ & & $(\mathbf{1}, \mathbf{1}, \mathbf{1})$ & $(1 / 2,1,2)$ & $(2,3,4)$ & $(1,2,3)$ & $(5,6,7)$ & $(1 / 2,1,2)$ \\
\hline$C 3$ & & & $(\mathbf{1}, \mathbf{1}, \mathbf{1})$ & $(2,3,4)$ & $(1,2,3)$ & $(4,5,6)$ & $(1,2,3)$ \\
\hline$C 4$ & & & & $(\mathbf{1}, \mathbf{1}, \mathbf{1})$ & $(1 / 3,1 / 2,1)$ & $(2,3,4)$ & $(1 / 4,1 / 3,1 / 2)$ \\
\hline$C 5$ & & & & & $(\mathbf{1}, \mathbf{1}, \mathbf{1})$ & $(4,5,6)$ & $(1 / 2,1,2)$ \\
\hline$C 6$ & & & & & & $(\mathbf{1}, \mathbf{1}, \mathbf{1})$ & $(1 / 4,1 / 3,1 / 2)$ \\
\hline$C 7$ & & & & & & & $(\mathbf{1}, \mathbf{1}, \mathbf{1})$ \\
\hline
\end{tabular}


By use of fuzzy numbers and FGP, selection becomes less dependent to the decision maker and human errors. Therefore, the results would be more reliable. The proposed methodology is employed for the coalmine in Soma (Turkey). Seven decision criteria and seven alternative transportation systems are determined. The most important criteria in selecting the transportation system are found to be transportation distance, inclination and ore reserve amount. Investment cost and unit cost are found to be less effective in transportation decisions. Finally, economic life of the mine and production capacity have very small effects on transportation mode selection. In addition, the most suitable transportation mode for the case under study is found to be belt conveyor system. Large capacity truck haulage is the second best performing system. The results of this study can be used for the new thermic power plant to be established in the region.

\section{References}

Çebi, Y. 1995. Computer Aided Design of Open-Pits and Middle and Long Term Mine Planning: PhD Thesis. The Graduate School of Natural and Applied Sciences, Dokuz Eylül University, Izmir, Turkey.

Chen, N.; Xu, Z. 2015. Hesitant fuzzy ELECTRE II approach: a new way to handle multi-criteria decision making problems, Information Sciences 292: 175-197. https://doi.org/10.1016/j.ins.2014.08.054

Demirsoy, M. 1984. Transport tekniği (Iletim makinalari): Cilt I. İzmir, Türkiye (in Turkish).

Dogru, T. 2005. Katıların hidrolik nakli, in S. Eskikaya, C. Karpuz, M. A. Hindistan, N. Tamzok (Eds.). Maden mühendisliği açık ocak işletmeciliği el kitabı, 465-472 (in Turkish).

Elevli, B. 2014. Logistics freight center locations decision by using fuzzy-PROMETHEE, Transport 29(4): 412-418. https://doi.org/10.3846/16484142.2014.983966

Içtenbaş, B. D.; Rouyendegh, B. D. 2012. A fuzzy AHP for evaluation of ecommerce websites performance, in Proceedings of the 3rd International Conference on Information Management and Evaluation: ICIME 2012, 16-17 April 2012, Ankara, Turkey, 57-62.

Karpuz, C. 2005. Açık ocak taşıma yolu tasarımı, in S. Eskikaya, C. Karpuz, M. A. Hindistan, N. Tamzok (Eds.). Maden mühendisliğ $i$ açık ocak işletmeciliği el kitabı, 431452 (in Turkish).

Kose, H.; Yalcin, E., Simsir, F.; Konak, G.; Onargan, T.; Kizil, M. S. 2009. Açık İşletme Tekniği. Dokuz Eylül Üniversitesi. Mühendislik Fakültesi yayınları, Türkiye (in Turkish).

Lizotte, Y. 1988. Economic and technical relations between open-pit design and equipment selection, in R. K. Singhal (Ed.). Mine Planning and Equipment Selection'98, 3-13.

Mahdevari, S.; Shahriar, K.; Esfahanipour, A. 2014. Human health and safety risks management in underground coal mines using fuzzy TOPSIS, Science of The Total Environment 488-489: 85-99.

https://doi.org/10.1016/j.scitotenv.2014.04.076

Malli, T. 2013. Yatırım teorileri kullanılarak yeraltı ve yerüstü maden işletme sınırının belirlenmesi: Doktora tezi. Dokuz Eylül Üniversitesi. İzmir, Türkiye. 107 s. (in Turkish).

Mikhailov, L.; Tsvetinov, P. 2004. Evaluation of services using a fuzzy analytic hierarchy process, Applied Soft Computing 5(1): 23-33. https://doi.org/10.1016/j.asoc.2004.04.001

Mizrak Ozfirat, P. 2014. Bulanik önceliklendirme metodu ve hata türü ve etkileri analizini birleştiren yeni bir risk analizi yöntemi, Gazi Üniversitesi Mühendislik Mimarlik Fakültesi Dergisi / Journal of the Faculty of Engineering and Architecture of Gazi University 29(4): 755-768 (in Turkish). https://doi.org/10.17341/gummfd.04423
Mizrak Ozfirat, P.; Ozfirat, M. K.; Malli, T.; Kahraman, B. 2015. Integration of fuzzy analytic hierarchy process and multiobjective fuzzy goal programming for selection problems: an application on roadheader selection, Journal of Intelligent \& Fuzzy Systems 29(1): 53-62. https://doi.org/10.3233/IFS-151569

Nahmias, S. 1997. Production and Operations Analysis. 5th edition. McGraw Hill Higher Education. 864 p.

Ozfirat, M. K. 2015a. Bantli konveyorler, Maden Ocak Teknolojileri 26: 30-32. (in Turkish).

Ozfirat, M. K. 2015b. Selection of tunneling machines in soft ground by fuzzy analytic hierarchy process, Acta Montanistica Slovaca 20(2): 98-109.

Ozfirat, M. K. 2012. A fuzzy method for selecting underground coal mining method considering mechanization criteria, Journal of Mining Science 48(3): 533-544. https://doi.org/10.1134/S1062739148030173

Rouyendegh, B. D. 2012. Evaluating projects based on intuitionistic fuzzy group decision making, Journal of Applied Mathematics 2012: 1-16. https://doi.org/10.1155/2012/824265

Rouyendegh, B. D.; Erkan, T. E. 2012. Selection of academic staff using the fuzzy analytic hierarchy process (FAHP): a pilot study, Tehnički vjesnik - Technical Gazette 19(4): 923-929.

Rouyendegh, B. D.; Lesani, S. H. 2014. Object-oriented programming language selection using fuzzy AHP method, in Proceedings of the International Symposium on the Analytic Hierarchy Process (ISAHP 2014), 29 June - 2 July 2014, Washington, DC, US, 1-17.

Saaty, T. L. 1980. The Analytic Hierarchy Process: Planning, Priority Setting, Resource Allocation. McGraw-Hill. 287 p.

Saltoglu, S. 2005. Kamyon taşımacılığı, in S. Eskikaya, C. Karpuz, M. A. Hindistan, N. Tamzok (Eds.). Maden mühendisliği açık ocak işletmeciliği el kitabı, 453-463 (in Turkish).

Simsir, F.; Tatar, C.; Ozfirat, M. K. 2013. Madenlerde nakliyat. Dokuz Eylül Üniversitesi, İzmir, Türkiye (in Turkish).

Thompson, T. L.; Raymer, F. B. 1981. Transportation, storage, and handling of coal, in M. A. Elliott, (Ed.). Chemistry of Coal Utilization, 523-570.

TKI. 2015. Işs Güvenliği ve Sağlı̆̆ı Şube Müdürlüğü, Eğitim Başmühendisliği, Tanttım notları. Ege Linyitleri İşletmesi Müdürlüğü (ELİ), Türkiye Kömür İşletmeleri Kurumu Genel Müdürlüğü (TKI), Soma, Manisa (in Turkish).

Walker, S. C. 2012. Mine Winding and Transport. Elsevier Science. $572 \mathrm{p}$.

Yegulalp, T. 2005. Bant taşımacılığı, in S. Eskikaya, C. Karpuz, M. A. Hindistan, N. Tamzok (Eds.). Maden mühendisliği açık ocak işletmeciliği el kitabı, 473-516 (in Turkish).

Yetkin, M. E.; Simsir, F.; Ozfirat, M. K.; Mizrak Ozfirat, P.; Yenice, H. 2016. A fuzzy approach to selecting roof supports in longwall mining, South African Journal of Industrial Engineering 27(1): 162-177. https://doi.org/10.7166/27-1-1366

Yuen, K. K. F. 2014. Fuzzy cognitive network process: comparisons with fuzzy analytic hierarchy process in new product development strategy, IEEE Transactions on Fuzzy Systems 22(3): 597-610. https://doi.org/10.1109/TFUZZ.2013.2269150

Yuen, K. K. F. 2012. Membership maximization prioritization methods for fuzzy analytic hierarchy process, Fuzzy Optimization and Decision Making 11(2): 113-133. https://doi.org/10.1007/s10700-012-9119-8

Zadeh, L. A. 1965. Fuzzy sets, Information and Control 8(3): 338-353. https://doi.org/10.1016/S0019-9958(65)90241-X

Zamorano, S. 2011. Surface ore movement, storage, and recovery systems, in P. Darling (Ed.). SME Mining Engineering Handbook, 977-987. 